\title{
A PESSOA HUMANA COMO PROTAGONISTA DA HISTÓRIA ÉTICA NA FILOSOFIA DE MARÍA ZAMBRANO
}

Arlindo Ferreira Gonçalves Jr.

\begin{abstract}
RESUMO
O referente artigo trata da recuperação dos argumentos da filósofa espanhola María Zambrano, em particular, nas obras em que expõe suas considerações acerca da noção de pessoa; e demonstrar como tal reflexão, engendrada na constituição da idéia de história do homem ocidental, assinala para o sentido ético da sociedade pela crítica ao poder do indivíduo que se encobre sob a razão do Estado. Nessa análise em que destaca a tragicidade do ocidental, faz mediante dois pares de contrários: indivíduo/pessoa e massa/povo, e elege a pessoa, enquanto povo, a protagonista de uma história ética.
\end{abstract}

PALAVRAS-CHAVE: Zambrano. Ética. Pessoa.

\begin{abstract}
This article treats to recoup the arguments of the spanish philosopher María Zambrano, in particular, in her texts which she displays its concerning about person notion; and to demonstre as such reflection, produced in the constitution of the idea of history of the occidental person, designates for the ethical direction of the society by the critical to the power of the individual that hides on the reason of state. In that analysis that she detaches the tragic
\end{abstract}

* Doutor em Filosofia pela Universidade Gama Filho. Professor de Filosofia da Faculdade de Filosofia da Pontifícia Universidade Católica de Campinas. 
condition of the occidental person, to emphasize two pairs of contrary: individual/person and mass/people, and chooses the person, while people, the protagonist of an ethical history.

KEYWORDS: Zambrano. Ethics. Person.

\section{Introdução}

A escola filosófica de inspiração orteguiana originada na Espanha do século XX sob a égide dos ideiais da geração de 1914, foi notoriamente marcada pela reflexão sobre a crise histórica e ética do homem contemporâneo. Discípulos diretos e indiretos do perspectivismo e raciovitalismo de Ortega y Gasset, sobretudo aqueles que vivenciaram o exílio no período franquista, contribuíram de forma prestimosa na constituição própria da filosofia latino-americana, se fazendo presente em diversos campos de atuação e possibilitando a construção de sua autenticidade intelectual. Dentre esses pensadores chamados "transterrados", que tiveram expressivo reconhecimento, está María Zambrano, autora com a qual nos acercaremos na presente pesquisa.

María Zambrano (1904-1991), espanhola de Vélez Málaga, tem sua filosofia mormente inspirada no pensamento de Ortega y Gasset, seu professor juntamente com Zubiri na Universidade Central de Madrid, ainda que o mescle com o intuicionismo bersoniano e o vitalismo de Unamuno. Podem-se dividir as fases da autora mediante determinados períodos que delimitaram a própria história contemporânea da Espanha.

O primeiro, de 1924 a 1939, foi consagrado aos estudos e aos trabalhos políticos. Participou como estudante do grupo que viria a ser denominado de Escola de Madrid. Período sob grande influência da fenomenologia de Husserl, Scheler e da descoberta da ontologia da vida humana. O principal marco institucional, que possibilita a articulação de atividades desse grupo, vem da reforma do Ensino Universitário ocorrida na Segunda República-em particular pelas ações dos ministros Fernando de Los Ríos e

Educ. e Filos., Uberlândia, v. 21, n. 42, p. 155-168, jul./dez. 2007. 
Marcelino Domingo-que se concretiza com a autonomia da Faculdade de Filosofia e Letras, na qual García Morente torna-se decano em 1932. Na época de sua instauração e estabelecimento (1933-1936) nota-se uma intensa atividade intelectual em diversos "centros editoriais" inaugurando um ambiente de discussão filosófica na Espanha. Centros, ou fundações, estes que funcionavam como aglutinadores e promotores de tendência periodista e participativa orientados por Ortega y Gasset e com a participação dos membros da Escola de Madrid, tais são os exemplos que se seguem: imprensa diária (El Imparcial, El Sol, Crisol, Luz); revistas España, El Espectador, Revista de Occidente); direção de coleções (Biblioteca de Idéias do Século XX); direção de órgãos políticos (Liga de Educação Política, Agrupación al Servicio de la República). Como núcleo básico a Escola de Madrid tinha a Secção de Filosofia da Faculdade de Filosofia e Letras. Seu período de maior atividade foi em 1935 - época em que se formam alunos ilustres como Julián Marías, Manuel Granell e Antônio Rodríguez Huéscar, e também de importantes adesões, tais como: María Zambrano (professora auxiliar), Recaséns Siches (catedrático de Filosofia do Direito), Joaquim Xirau (decano da Faculdade de Filosofia e Letras de Barcelona). Com a era franquista tem-se o exílio e a dissolução. Neste contexto a Escola de Madrid se divide entre os membros que se mantiveram na Espanha (Julián Marías, Morente) e os exilados na América de (José Gaos, Recaséns Siches, Manuel Grannel, María Zambrano e Aranguren), porém, em sentido estrito tenha desaparecido sua unidade ao dissolver-se a plataforma universitária da qual operava, e também por haver Ortega y Gasset renunciado voluntariamente sua liderança - apesar de encontrarmos preservados, no nosso entender, traços perenes de sua filosofia naqueles que foram seus discípulos diretos.

Como resultado dessa primeira fase temos vários artigos de teor político, em que Zambrano dedica-se à defesa republicana e nacionalista da Espanha, textos que posteriormente serão compilados na obra Los intelectuales en el drama de España y escritos de la guerra civil (1998).

O segundo período da autora refere-se ao seu exílio latino- 
americano, dentre os anos de 1939 e 1953, em que exerceu atividades nas universidades do México, Cuba e Porto Rico. São destaques dessa fase: "Filosofía y poesía" e "Delirio y destino: Los veinte años de una española".

É no último período da autora passados na Europa, de 1953 até sua morte, em 1991, que se encontram suas obras mais importantes. Em El hombre y lo divino (1955), a autora trata das origens do sagrado na Grécia antiga e no cristianismo, e assinalando as diferenças com o conceito de divino. Na obra Persona y democracia - la historia sacrificial (1958), temos apresentadas suas críticas ao racionalismo ocidental, e as implicações éticas da pessoa na história. Em 1965, em España, sueño y verdad, recorre a ensaios literários com temáticas predominantemente espanholas. Em Notas de un método de 1989, a autora volta à crítica ao racionalismo, perspectiva esta que coincidirá com as correntes pós-modernistas, recuperando argumentos de Ortega y Gasset e Nietzsche. Também cabe apontamento nesta fase a obra Claros del bosque (1988) em que a autora reflete sobre a valorização da revelação como via de compreensão.

A partir do segundo período supramencionado é articulado o conceito-chave do pensamento da autora que passará a ser o lastro para toda sua filosofia posterior: a razão poética. Seu projeto intelectual propõe-se a superar as crises geradas pelo racionalismo cartesiano através de uma teoria do conhecimento reformulada no sentido de buscar um "saber inaugural" e criador para apreensão da realidade, não pelas categorias do entendimento racional-discursivo, mas através do próprio argumento da "vida poética". Fundamentada sobre este princípio teórico é que Zambrano dirige sua crítica cultural ao ocidente e assinala para a desintelectualização do modelo de razão consagrado na modernidade. Neste sentido destacam-se as influências da Geração de 98, em particular as de Unamuno e Ganivet, bem como a do primeiro Ortega, quando estes ao preocuparem-se com o sentido essencial da idéia de Espanha - a essencialidade hispânica - a consideram como expressão do irracional frente à uma Europa ilustrada. No projeto de "espanholizar a Europa" e "europeizar a

Educ. e Filos., Uberlândia, v. 21, n. 42, p. 155-168, jul./dez. 2007. 
Espanha", é que reside o debate entre as antinomias criadas pela desvitalização da razão e pela idealização da vida, e se situa o ponto de partida para a crítica que irá permear o pensamento da autora.

Trataremos neste artigo de destacar os argumentos da filósofa espanhola María Zambrano, em particular, nas obras em que expõe suas considerações acerca da noção de pessoa; e demonstrar como tal análise, engendrada na constituição da idéia de história do homem ocidental, e que tem a violência como um dos seus fundamentos, assinala para o sentido ético da sociedade pela crítica ao poder do indivíduo que se encobre sob a razão do Estado.

A práxis histórica da pessoa humana segundo a filosofia de Maria Zambrano

As reflexões que sustentam as posteriores aproximações à noção de pessoa na filosofia de María Zambrano, já aparecem projetadas desde sua primeira obra El nuevo liberalismo ${ }^{1}$ (1930). Isto porque tal idéia é inscrita no âmbito da política, que por sua vez é concebida como atividade humana que objetiva a criação prospectiva, atividade essa entremeada com a religião e a ética (ORTEGA MUÑOZ, 1994). O projeto político, que visa realizar esse programa vital humano, portanto dirigido ao futuro, deve ter como lastro a história, como sustenta a autora:

Toda política supone idealmente una consciencia histórica; es su alumbramiento; se dirige a un futuro, lo crea. $\mathrm{Y}$ como actividade humana, es de trayectoria posible, y no necesaria, porque en lo humano existe la gloria y la tragedia de la posibilidad, de la indeterminación. Y de no ser así, no habría política; tampoco habría historia (ZAMBRANO, 1996, p. 204).

1 Trabalho reeditado em 1996, sob o título de Horizonte del liberalismo pelas Ediciones Moratas, possui um excepcional estudo introdutório: La politica desde su envés histórico-vital: história trágica de la esperanza y sus utopías, por Jesús Moreno Sanz. 
Neste sentido tem a política uma dupla face: uma voltada ao passado, imersa no "subconsciente histórico"; a outra mantem o olhar para a trajetória do vir-a-ser de realização, para o "quefazer" transformador. Daí seu caráter intrinsecamente revolucionário, compreendido pela autora nos termos que se seguem:

Una política de esencia revolucionaria no significa necesariamente una revolución, con su brusquedad de catástrofe, con la crueldad de sus procedimientos audaces...y con sucedáneo retroceso. Más bien diríamos que la excluye, en tanto que la presupone de un modo continuo, de cada día, de cada hora. La revolución es un procedimiento que tanto puede efectuarse para abrir paso a una política revolucionária, como a outra de la más hermética esencia conservadora. [...] Una revolución depende, no de una doctrina, y sí de un estado social (ZAMBRANO, 1996, p. 221).

A política em instância primeira pode ser apresentada como um determinado modo de ingerência no plano vital, objetivando introduzir uma mudança através de direcionamentos planificados. Ao explicar a política em termos de "atividade" frente à vida, salienta-se a necessidade de distingui-la do seu costumaz e restrito propósito de vontade de poder, do qual a autora atenta em dizer que: "[...] o poder pode ser a raiz mediante a qual se insere em alguns indivíduos esta atividade; mas ela em si mesma, se anseia o poder, é para a reforma" (ZAMBRANO, 1996, p. 2003).

Destina-se à política, portanto, à reforma do presente em sentido estrito, sinalizando as condições para o devir forjado pela intervenção e mobilizado pelo inconformismo. Nutre familiaridade com a religião e a ética, mas obsta destas por se efetivar necessariamente, e por excelência, na dinâmica mesma da sociedade. O projeto político reformista, como parte da dimensão humana que visa realizar o programa vital, portanto dirigido ao futuro, deve ter como lastro a história.

Cabe a cada circunstância geracional arquitetar suas ações a partir de sua cosmovisão, de sua "orbe espiritual", ou seja, construir

Educ. e Filos., Uberlândia, v. 21, n. 42, p. 155-168, jul./dez. 2007. 
uma política determinada para sua vocação inalienável. Não obstante, a cultura contemporânea está consciente da necessidade de situar a pessoa como o centro originário tanto da sociedade como da própria história.

O conceito de pessoa, com o qual nos acercaremos, ocupa dentre outros assuntos, os textos de Zambrano que versam sobre o conceito de História e o problema da Europa. Em La agonía de Europa (1945), El hombre y lo divino (1955) e, em especial, Persona y democracia (1958), a autora aborda tal noção através de um enfoque social e político, com escopo de identificar as implicações éticas envolvidas na sucessão da idéia de história permeada no transcorrer do desenvolvimento da Europa.

O significado da noção de pessoa, emanado primordialmente do próprio teatro - persona -, teve lugar no debate filosófico quando elevou-se à entidade jurídica, instante em que foi amplamente discutido precisamente pela sua estrutural associação à dimensão moral, o que ocorreu no alvorar da tradição moderna, especificamente a partir de Locke. Já este filósofo assinala a noção de identidade como o fulcro pelo qual a pessoa é definida e particularizada, o que posteriormente será consagrado pelo pensamento kantiano, que sublinha o pressuposto intrínseco da sua condição de portadora de valor. Tal perspectiva se fará passar ao longo da modernidade com a idéia de que aquela entidade individualizada é detentora da capacidade de integrar-se, desvelar o si-mesmo, e transcender-se no tempo, projetando seu próprio esquema intencional. $\mathrm{O}$ exórdio histórico no qual partimos para essa compreensão tem como pano de fundo a gênese da subjetividade, da consciência da singularidade. O homem descobre a "autobiografia" no Renascimento, pois descobre-se protagonista de uma narrativa da que passa ter nas mãos privilegiadas - e secularizadas - a autonomia de governo. Não por acaso, o personagem homérico, Odisseu, ressurge copiosamente divulgado. A Odisséia é a jornada do ego que busca o regresso a si-mesmo sem jamais deixar escapar da memória daquele que volta ao reino de Ítaca, quem de fato partiu, e para aquilo que voltará.

Transcendendo a sociedade e a história, a pessoa, para nossa 
autora, é definida como o ente que inclui o eu, o indivíduo e o personagem. $\mathrm{O}$ verdadeiro ethos da pessoa reflete seu agir em função do si-mesmo, tendo articulado de maneira autêntica as três dimensões mencionadas, a despeito de que não se confunde quando comparada com cada uma dessas categorias. Na sua constituição própria, a pessoa é compreendida por essa conjugação de aspectos essenciais: uma realidade pessoal, ou fundo inexorável, denominado pela autora de "entranha"; nosso vínculo com a realidade em forma de personagem para aquilo que nos rodeia; e nosso eu, como consciência de ser e manifestação do agir livre.

A pessoa real não se esgota naqueles aspetos constitutivos, mas os integra no viver. O personagem representa a imagem espelhada e inventada de nós mesmos, a máscara da inadequação daquilo que se é em realidade, em outros termos, representa o ser manifesto da alteridade. Do mesmo modo como não se encerra na condição de indivíduo, a ultrapassa, pela consciência de si e pela liberdade. Ao associar a noção de pessoa com o próprio agir livre e responsável, a autora recupera a tradição orteguiana que inspirou os próprios movimentos existencialistas, ao sustentar a liberdade como condição primordial da vida humana, que em sua estrutura primeira é indigente e carente de modelos prévios, estando o homem forçado a atender à sua vocação (ORTEGA Y GASSET, 1961).

É a sociedade o lugar em que o indivíduo tão somente pode se realizar. Essa realização se faz em uma constante tensão dialética entre o estado de alteração, de convívio, e o de solidão radical, ou ensimesmamento. Ser pessoa é ser solidão, e como diz a autora: “[...] una soledad dentro de la convivencia [...]. Por ello, nadie que viva como persona puede estar enteramente adherido a modo de vida alguno. El lugar del individuo es la sociedad, pero el lugar de la persona es un íntimo espacio" (ZAMBRANO, 2004, p. 157). Cabe ressaltar que Zambrano não alude aqui ao individualismo solipsista e anti-histórico, mas assinala para o reconhecimento da sociedade como a presença necessária do passado, enquanto a pessoa é a obra aberta ao futuro imprevisível (ORTEGA MUÑOZ, 1994). Neste sentido, o espaço privilegiado de efetivação do humano é um determinado tipo de sociedade, a democrática. A 
mesma ambiência que pode conduzir ao seu posto adverso, o absolutismo, como assinala na seguinte passagem:

la marcha de Occidente ha ido inexorablemente encaminada hacia esta sociedad. Pero esta misma fe humanista ha edificado el mayor de los obstáculos para la realización de esta sociedad que le sea adecuada: el absolutismo [...] el absolutismo occidental tan diverso de los despotismos orientales, que comienzan con el endiosamiento de los emperadores romanos hasta los días de hoy en que acabamos de asistir a su caricatura: los totalitarismos de Estado que, paradójicamente y extrañamente, han comportado el endiosamiento de un personaje, cosa en verdad sorprendente (ZAMBRANO, 2004, p. 77-78).

A autora destaca, porém, as limitações da democracia, como a demagogia e o uso ilegítimo da ideologia, e as conseqüências de quando a democracia torna-se totalitária, pela exaltação da uniformidade das massas. Influenciada uma vez mais pela filosofia orteguiana, em especial pelas obras do final da década de 1920, que demarcam o trânsito para a etapa que posteriormente irá confirmar a razão histórica no pensamento daquele autor, María Zambrano acolhe as considerações apresentadas em La rebelión de las masas (1929). Tal influência é observada na própria definição do que a autora pondera ao se referir à idéia de massas, considerando-a como o modo de agir irresponsável do homem, cuja influência coercitiva pelas heteronomias, deflagra a vida impessoal e inautêntica - o das-Man a que se refere Heidegger.

Consideraremos agora a relação do exposto supramencionado com o conceito de história, a fim de cumprir nosso propósito. É na idéia mesma de História que se propagam as insuficiências éticas geradas na Europa, em particular, a deterioração da concepção de pessoa. Caberá uma consciência histórica que torne patente a continuidade do passado que se impõe na forma de difusão da violência, objetivando a perspectiva ao futuro.

Por meio da incursão sobre o conceito de História, este adquire 
um significado original no pensamento de nossa autora: "História como Tragédia". Figurando como "primeira e ineludível questão" colocada para o ocidente, este é o problema que norteará as discussões de María Zambrano, particularmente nas bases para sua formulação de uma filosofia da história: "Cuál es el origen trágico de nuestra historia y por qué há sido trágico $\mathrm{y}$, en consecuencia, el dintel que hemos de sobrepasar?" (ZAMBRANO, 2004, p. 52).

A História refere-se ao modo de como o humano subleva-se sobre sua condição original e, criando-se em um horizonte prospectivo, inventa sua própria natureza. A autora propõe um esquema de interpretação histórica, pelo qual poderá ser desvelado o agir livre da pessoa, como mostra no seguinte trecho:

[...] vamos a proponer un esquema de este conocimiento de la historia, de la propria historia, de aquella de la cual somos actores, que sea al proprio tiempo libertad. El tránsito de un modo trágico de hacer la historia al modo libre: de una historia trágica a un historia ética(ZAMBRANO, 2004, p. 80).

Utilizando-se de uma hermenêutica do processo constitutivo do ocidente, a autora aponta três momentos em que o homem impulsiona e concebe diferentemente a História: o primeiro teria ocorrido na passagem do universo mítico-divino ao humano, em que encontra seu problemático lugar no cosmo que o impele à história; posteriormente, a história se revela no modelo elaborado na teoria cristã de Santo Agostinho, e que sustentará a própria constituição da idéia de Europa; o terceiro momento seria o século XIX, quando o homem ocidental decide pela suplantação da dimensão do divino, e se submete integralmente à realidade irredutível da história.

O primeiro momento, a Grécia antiga com seu culto à razão, à paidéia helênica, põe em marcha o que se denomina de "rebeldia" ante às limitações e determinismos da própria condição humana. Desde então recorrem à razão, ao Ser inexorável, a fim de superar o real, frente ao drama da finitude. Divorciado do divino, mas

Educ. e Filos., Uberlândia, v. 21, n. 42, p. 155-168, jul./dez. 2007. 
desamparado e irremediavelmente só, o homem, na figura do filósofo se aprofunda pelo conhecimento na condição precária dessa fragilidade essencial.

Se a consciência da finitude influi na perspectiva do helênico sobre si, recai também sobre ele a ameaça da morte pessoal; e a proximidade com a verdade em um mundo seguro e perene, o eterniza, a razão o imortaliza. Esse desejo à imortalidade levou à construção do discurso racional, ou à filosofia, uma vez que imortal é a natureza e seu fundamento, o logos, e este figura sobre dois enfoques quanto à physis: seu sentido primeiro, bem como a capacidade racional de conhecê-la. Tal discussão sobre o tema da imortalidade entre os gregos encontra lugar também na filosofia de Hannah Arendt, como assinala Fernández Martorell: “Arendt y Zambrano coinciden en afirmar que los griegos invetaron la imnmortalidad, pero no consiguieron darle una solución y dejaron al ser humano desamparado y solo en su propia racionalidad" (ZAMBRANO, 2004, p. 32).

No segundo momento, o cristianismo reorienta o sentido de imortalidade convertendo a natureza como algo passageiro, e o homem no ser que se eterniza. Assim a natureza, imperfeita e fugaz, representa já um obstáculo ao ser do homem, e o que fundamenta tal horizonte compreensivo é a religião semita na forma de duas premissas norteadoras: "a vida é sagrada" e "o homem é o ser supremo sobre a terra". Reside aí, segundo Zambrano (1988), a origem da história e do pensamento próprio da Europa através do cristianismo, no sentido de que o homem é concebido como aquele que, situado no lugar privilegiado da criação, pode criar a si mesmo. Este é o seu autêntico impulso, conforme a autora:

[...] hacerse un mundo desde su nada.[...] No se conforma com la vida, ni siquiera con la inmortalidad, que es perdurar sin huesos, separarse de sus propias entrañas. [...] Si el hombre es ceniza, polvo nada, tiene que crearse también su mundo como hizo Dios cuando estaba solo (ZAMBRANO, 1988, p. $41)$. 
O modelo divino tem reincidência no homem que cria desde o nada, pela sua rebeldia, e através de manifesta "violência". Nesse sentido sustenta Zambrano que a história da Europa é engendrada de violência, seu próprio motor, posto sua origem no mito da criação. A autora compreende que o ocidente é protagonizado por "personagens-máscaras", verdadeiros autores da violência, são os que sentem detentores de prerrogativas, elevados acima da moral, e acima de sua condição de pessoa, ou seja, crêem no seu endeusamento ilimitado.

Despojados desses limites como pessoa, e traspassados pelo ressentimento primário desde sua finitude, o homem ocidental, encantado pelo endeusamento, produz a fascinação das massas e minorias, naquele fenômeno já descrito pela autora como absolutismo, como o fundamental contraponto à constituição da pessoa: "El absolutismo es nuestro gran pecado, porque en él, con él, negamos lo mismo que queremos: el que la persona se realice íntegramente" (ZAMBRANO, 2004, p. 89).

Nesta análise em que destaca a tragicidade do ocidental, o faz mediante dois pares de contrários: indivíduo/pessoa e massa/ povo. Enquanto o indivíduo, que vive como personagem, subtrai seu aspecto pessoal no Estado como massa irrefletida, a pessoa tem resguardado seu locus de intimidade, o que a possibilita criar para a história. Quando o povo está reduzido à massa, diz a autora:

[...] se presenta por el pronto como un hecho bruto; algo que está ahí. Y como está vivo, el hecho bruto de la vida es la avidez, la avidez sin fin, la ilimitada avidez que sustituye al hambre antigua. La masa satisfecha es ávida de bienes materiales y de no se sabe qué. Pues como es humana, siente el vacío (ZAMBRANO, 2004, p 184).

Somente a pessoa, como povo, é que pode protagonizar uma história ética através da democracia e se contrapor à violência criadora, sua condição sacrificial, ou nos termos da autora: "[...] sólo de vivirá moralmente cuando se haya vencido esta tendencia espontánea a la destrucción. Cuando el hombre haya salido de

Educ. e Filos., Uberlândia, v. 21, n. 42, p. 155-168, jul./dez. 2007. 
este modo de vida en que es espontáneamente destructor, vivirá del todo moralmente" (ZAMBRANO, 2004, p. 83). Outrossim esse mesmo, o povo, deve ser o possuidor do si mesmo, legitimamente lídimo, perante o tecido entramado pelas massas.

\section{Considerações finais}

Neste sentido, a título de conclusão, podemos ressaltar a contribuição do pensamento da autora para uma atual proposição da noção de humanismo, uma vez que seu exame é sobremodo contemporâneo. Assinala para os conflitos deflagrados na pósmodernidade, já anunciados por gerações anteriores e persistentemente debatidos nas filosofias vigentes do século $\mathrm{XX}$, especificamente encontra lugar quando se refere ao conceito de crise. É, portanto, dessa crise do homem, ou seja, da insuficiência de sua identidade moral, da deterioração dos paradigmas de valores autênticos, e das variadas formas ilegítimas de representação do poder sobre o outro, que teremos o humano fragmentado, não consciente de si próprio e de sua inserção histórica. Deste modo, o humanismo a que a autora nos apresenta, tendo em vista as vicissitudes do homem ocidental coeso, alude antes à recuperação da noção de pessoa como ente por excelência da práxis - reflexivo e atuante -, ou seja, não como vítima, mas como protagonista moral da história.

\section{Referências}

ENKVIST, Inger. Pensadores españoles del siglo XX: una introducción. Rosario: Ovejero Martins, 2005.

FERNÁNDEZ MARTORELL, Concha. María Zambrano: entre la razón, la poesía y el exilio. Madrid: Montesinos, 2004.

MARÍA BENEYTO, José; GONZÁLEZ FUENTES, Juan A. (Coord.). María Zambrano: la visión más transparente. Madrid: Trotta/ Fundación Carolina, 2004. 
ORTEGA MUÑOZ, Juan Fernando. Introducción al pensamiento de María Zambrano. México: F.C.E., 1994.

ORTEGA Y GASSET, José. Que é filosofia? Rio de Janeiro: Livro Ibero-Americano, 1961.

ZAMBRANO, María. La agonía de Europa. Madrid: Mondadori, 1988.

. El pensamiento vivo de Sêneca. 2. ed. Madrid: Cátedra, 1992.

. Horizonte del liberalismo. Madrid: Morata, 1996.

. El hombre y lo divino. 2. ed. México: F.C.E., 2002.

. Filosofía y poesía. 4. ed. México: F.C.E., 2002.

. Persona y democracia: la historia sacrificial. 2. ed. Madrid: Siruela, 2004.

Los bienaventurados. 2. ed. Madrid: Siruela, 2004.

Pensamiento y poesía en la vida española. Madrid: Biblioteca Nueva, 2004.

Hacia um saber sobre el alma. Buenos Aires: Losada, 2005. 